A brief account of the history and development of the telescope is given in the first chapter.

The frontispiece of the book is a picture of the author's 6 -in. $f / 9$ telescope, with equatorial head and tripod mounting; made in accordance with the instructions in this book, it is stated to have cost less than thirty dollars. It may be recalled that William Herschel first embarked upon telescope construction because he could not afford to buy one for himself. With the aid of this book, many a budding astronomer should be able to construct his own telescope at a moderate cost.

\section{Aircraft Strength of Materials}

By Dr. H. D. Conway. Pp. viii +256. (London : Chapman and Hall, Ltd., 1947.) 21s. net.

R. CONWAY has produced a book that should be valuable to both students and designers dealing with aircraft structures, but its title is misleading. It is entirely a work on the theory of structures, its secondary connexion with aircraft boing that those problems that are of most interest in that field have been chosen, and the illustrative examples are such as occur in the peculiar types of structure occurring in aircraft construction. A critic could quarrel with the author for his sins of omission rather than commission, but incompleteness is inevitable in a book of this size. Also the science of the design of aircraft structures is so fluid at present that a selection of methods is bound to be one based on the author's personal experience. This defect is most noticeable in the part devoted to the behaviour of thin plates, which might have been much fuller. Its application to Wagner beams and stressed skin construction can scarcely be avoided to-day in the aircraft world; even the engine designer is meeting it now in the internal combustion turbine.

The layout of the book is excellent and logical. The chapters follow in an ordered sequence, and are well illustrated with numerical examples, particularly useful to a beginner. The more recent methods of structural analysis, such as the Hardy Cross method, are fully explained. This alone puts the book in a class by itself so far as an aeronautical reader is concerned.

The author has the courage to say that he has not tried to avoid the use of mathematics, claiming that no serious aircraft designer could be without such knowledge, a statement with which the reviewer heartily agrees.

\section{Electronic Theory and Chemical Reactions}

An Elementary Treatment. By R. W. Stott. Second edition, revised. Pp. viiit 112. (London, New York and Toronto: Longmans, Green and Co., Ltd., 1947.) 6s. net.

THE development of electronic theories of the mechanism of reactions has reached a stage at which it is possible to give useful general accounts of the main features, and there are indications of a rapidly growing interest in the subject. This interest has now deeply penetrated not only the ranks of teachers of chemistry who have a regard for major theoretical developments, but also the harder core of chemists in industrial and other fields who attach greater importance to tangible applications and concrete results.

The publication of a second edition of Mr. Stott's elementary treatment will be greeted with pleasure by those who were unable to obtain a copy of the first issue. This edition is almost identical with the first (see Nature, 153, 510; 1944); at a time when the prices of many commodities are rising steeply and continuously it is a pleasure to note that the old price is retained.

E. D. HuGHES

\section{Mechanical Vibrations}

By Prof. J. P. Den Hartog. Third edition. Pp. xi+ 478. (New York and London: McGraw-Hill Book Co., Inc., 1947.) 30s.

EN HARTOG'S book combines mathematical
simplicity with a rare insight into the physical nature of vibrations, and its author has a happy knack of explaining things in a way that the less gifted can understand. For these reasons, and for the wealth of information it contains, the book has long been a standard work in Great Britain as well as in the United States.

The present edition includes observations on helicopter rotors, the 'singing propeller' and oscillations of submarine periscopes. Electronic methods of vibration measurement and analysis, the damping of torsional oscillations in engine crank-shafts, oscillations excited by oil-film lubrication and 'flutter' are among important subjects which are discussed more fully in the light of recent work. This is a book of which no mechanical engineer should be unaware, and which those faced with vibration problems find of constant help.

A. L. P.

\section{Modern Assembly Processes}

Their Development and Control. By J. L. Miller. Second edition revised. Pp. xiit 199. (London : Chapman and Hall, Ltd., 1946.) 18s. net.

$\mathrm{TN}$ this new edition of his book, Mr. Miller has taken advantage of war-time experience to bring certain sections up to date; modern aircraft riveting practice in flush riveting and the invaluable pop riveting technique are described, for example. The descriptions of fluxes for soft soldering are considerably expanded and include recommendations for the lead/silver solders and the low-tin solders of B.S.219. Brief details are given of the newer welding processes such as Heliarc, the Elin-Hafergut process and automatic stud-welding machines. Apart from these additions, the book remains substantially the same as in the first edition and is still the only one available covering its specialized field. Mr. Miller has resisted all temptation to extend its scope, wisely preferring to restrict his words to the subjects on which his authority is undoubted. H. W. G. H.

\section{Foundations of Chemical Theory}

By Charles Simpson. Pp. viiit220. (London: University Tutorial Press, Ltd., 1947.) 6s. 6d.

THIS book aims at giving a concise account of the main principles of theoretical chemistry required for higher school certificate, intermediate science, pre-medical and first M.B. examinations, and providing a foundation for distinction and scholarship students. It actually contains rather less on many topics than is usually found in general text-books of this stage. More space is given to phase rule than is usual. A good feature of the book is the large number of questions and problems, which will provide useful exercises for students. Unfortunately, the book is marred by a number of minor errors, and in places insufficient detail is given to enable students to understand the principles of some experimental methods described. In a new edition the book should be carefully revised. 